\title{
Morphological and physiological adjustments of Brazilwood (Caesalpinia echinata Lam.) to direct solar radiation
}

\section{Liana Hilda Golin Mengarda ${ }^{1}$, Camilla Rozindo Dias Milanez ${ }^{1}$, Diolina Moura Silva ${ }^{1}$, Marco Antonio Galeas Aguilar ${ }^{1,2}$, Geraldo Rogério Faustini Cuzzuol1*}

\author{
1Programa de Pós-graduação em Biologia Vegetal, Departamento de Ciências Biológicas da Universidade \\ Federal do Espírito Santo (UFES), Vitória, ES, Brasil. \\ ${ }^{2}$ Comissão Executiva do Plano da Lavoura Cacaueira (CEPLAC), Linhares, ES, Brasil. \\ Corresponding author: gcuzzuol@gmail.com \\ Received: 1 March 2012; Accepted: 5 September 2012
}

\begin{abstract}
This study aimed to characterize the alarm and resistance phases of stress of Caesalpinia echinata under intense irradiance in order to better define its position on forest succession. The alarm phase was identified by rapid reduction in the maximum quantum yield of PSII primary photochemical reactions $\left(\phi P O=F_{V} / F_{M}\right)$ and Performance Index $\left(P_{A B S}\right)$ followed by total leaf abscission in the first week of exposure to direct sunlight. The new leaves grown showed recovery of chlorophyll a parameters, increase in blade thickness, elongation of the palisade and spongy parenchymas, higher water content, and reduction of specific leaf area. These changes were associated with the osmoprotector of sucrose and antioxidative of raffinose effects, which indicate an efficient adjustment system to intense irradiance in the resistance phase of stress. However, the continuous decrease in photosynthetic pigments in the resistance phase combined with the photodamage in the fluorescence of $\mathrm{Chl}$ a and total abscission of leaves in the alarm phase are strong indications that $C$. echinata is a shade and late or climax species in forest succession.
\end{abstract}

Keywords: forest succession, light stress, photoinhibition, leaf anatomy, soluble carbohydrates.

\section{INTRODUCTION}

There are few shade-tolerant species or shade plants that can survive in highly illuminated environments (Niinemets et al., 1998; Kitao et al., 2000). Some can overcome the critical stage of stress by intense irradiance due to its phenotypic plasticity (Gonçalves et al., 2005). Based on the model of Stocker (1947), the stress goes through phases, starting with the alarm characterized by the loss of functional and structural stability. With prolonged stress, these disorders are removed in the following phase of resistance.
The plant's capacity to overcome the alarm phase is the result of combining physiological, morphological and biochemical adjustments. Physiological adjustments are mediated by primary and secondary messengers. Among the primary messengers, the carbohydrates of low molecular weight such as glucose, fructose and sucrose are considered important molecular flags (Gibson, 2004; Nishizawa et al., 2008) associated with osmoregulation in leaf tissue under intense irradiance (Aranda et al., 2001; Valladares et al., 2005).

More recently, attention has been given to the role of raffinose on the mechanisms of resistance to stress 
(Nishizawa et al., 2008). Raffinose is a trisaccharide that, along with stachyose and verbascose, is part of the Raffinose Family of Oligosaccharides (RFOs), which are synthesized from sucrose (Peterbauer and Richter, 2001). The RFOs, together with mono and disaccharides, were related to the antioxidant, scavenging reactive oxygen species (ROS) in plants under stress (Nishizawa et al., 2008).

Carbohydrates can also modify leaf morphology. There are indications that the number of layers of palisade is induced by higher leaf concentration of sucrose (Terashima et al., 2006). The specific leaf area (SLA) is also subject to variations in the concentration of soluble carbohydrates combined with intense irradiance (Lambers and Poorter, 2004). In some trees, SLA (Valladares et al., 2005) and the concentration of carbohydrates (Marenco et al., 2001) increased in plants under full sunlight.

The physiological adjustments of shade plants when exposed to high radiation also involve the decreased concentration of total chlorophyll (Chl total $_{\text {) }}$ ) or an increase in the ratio of xanthophylls and violaxanthin cycle in relation to $\mathrm{Chl}_{\text {total }}$ (Wyka et al., 2007; Melgar et al., 2009). Under intense irradiance, some trees present inhibition of photosystem II (PSII) electron transport associated with the higher concentration of carbohydrates (Valladares et al., 2005; Melgar et al., 2009) and increased levels of flavonoids (Tattini et al., 2006).

Morphological and physiological changes in response to variations in irradiance intensity are well documented for leaves of trees in temperate zones (Matsuki et al., 2003; Valladares et al., 2005; Urban et al., 2007; Wyka et al., 2007). For the tropical trees, especially those native to Brazilian forests, there are increasing ongoing investigations which will bring answers in the medium term (Souza and Válio, 2003; Gonçalves et al., 2005; 2007; Mengarda et al., 2009).

Brazilwood (Caesalpinia echinata Lam. Fabaceae: Caesalpinioideae) is an endangered semi-deciduous tree species with composed leaves, native to the Brazilian tropical rainforest. Its heartwood is used for manufacturing bows for string instruments of renowned international quality (Longui et al., 2010). Under direct solar radiation, C. echinata showed leaf abscission within 72 hours of exposure and decrease in photochemical efficiency of PSII (Fv/Fm), which allowed Mengarda et al (2009) to consider this species as moderately shade-tolerant.

This study aimed at characterizing morphologically and physiologically the alarm and resistance phases of
C. echinata plants when exposed to intense irradiance. The data obtained are intended to define the habit of $C$. echinata regarding the application of light and its position in forest succession more accurately.

\section{MATERIAL AND METHODS}

Plant material and experimental design: Plants of Caesalpinia echinata Lam. (Fabaceae Caesalpinioideae) were grown for two years in $8 \mathrm{~L}$ plastic pots containing forest soil from the city of Aracruz, ES, Brazil $\left(19^{\circ} 49^{\prime} 10^{\prime \prime} S\right.$ and $\left.40^{\circ} 16^{\prime} 27^{\prime \prime} W\right)$. The plants were kept in a greenhouse at the Federal University of Espírito Santo, Vitória, ES, Brazil (20¹8'52"S and $\left.40^{\circ} 19^{\prime} 06^{\prime \prime} \mathrm{W}\right)$ under natural environmental conditions, average temperature $27 \pm 2^{\circ} \mathrm{C}$, natural photoperiod of $11 \pm 1 \mathrm{~h}$ and photosynthetically active radiation (PAR) of 250-350 $\mathrm{mmol} \mathrm{m} \mathrm{m}^{-1}$ measured with a quantum meter (Spectrum Technologies, Inc) at $900 \mathrm{~h}$ for five days without clouds. Six trees remained under these conditions of low solar radiation intensity while other plants were transferred to full sun (PAR 1,800-2,000 $\mu \mathrm{mol} \mathrm{m} \mathrm{m}^{-1}$ ). To avoid heat and excessive water loss by evaporation, the pots were covered with aluminum foil and the soil surface was covered with vermiculite. Plants were watered once a day with about $500 \mathrm{~mL}$ per pot.

The experimental design was completely randomized with five replications and six plants per plot in a factorial arrangement (2x12), consisting of two treatments (shade and full sun) and twelve sampling periods. The morphological, anatomical and physiological secondary leaflets were formed in the middle region of the first fully expanded leaves at $0,2,4,7,14,20,30,40,50,60,120$ and 180 days beginning the start of the experiment.

Leaf morphology: For each experimental time, leaflet fresh weight was determined after its removal from the tree, while dry weight was determined after drying leaflets for five days in an oven at $60^{\circ} \mathrm{C}$. Leaf area was determined using a Leaf Area Meter (LI-COR 3100C, Nebraska, USA). The collected data were used to calculate the specific leaf area (SLA $=L A / D W)$, as described by Hunt (1982). Water content was calculated by the equation $\mathrm{H}_{2} \mathrm{O}=\mathrm{FW}$-DW/LA, established by Parida et al. (2004), in which FW = fresh weight, $\mathrm{DW}=$ dry weight and $\mathrm{LA}=$ leaf area.

Leaf anatomy: The anatomical analyses were conducted using segments of the middle third of the lamina $(5 \times 5 \mathrm{~mm})$ fixed in FAA 50 (formaldehyde, acetic acid and ethanol) for $48 \mathrm{~h}$ (Johansen 1940), and stored 
in alcohol $70 \%$. Subsequently, samples were dehydrated in increasing ethanol series, and embedded in historesin (Leica Historesin ${ }^{\circledR}$ ), according to Gerrits (1991). Cross sections ( $9 \mathrm{~mm}$ thick) were made with a rotary microtome, further stained with toluidine blue $0.05 \%$, pH 4.7 (O'Brien et al., 1964) and mounted between the blade and coverslip in Canada balsam. The thickness of the lamina, the cuticle, the abaxial epidermis, and the palisade and spongy parenchyma were measured. Stomatal density $\left(\mathrm{mm}^{2}\right)$ was determined for the abaxial side using a printbased cyanoacrylate ester adhesive. Measurements were performed using the TSView v.6.1.3.2 (Tucsen Imaging Technology Co. Limited) image analyzer. Mean values were obtained from 20 measurements for each characteristic and the data was documented with a microscope (Nikon, E200, Japan) fitted with a digital camera (Sony 7.2 megapixels).

Histochemistry: To determine the chemical nature of the cell wall and cell content, free-hand cutting sections of fresh material, obtained after 180 days of the experiment, were tested with the histochemical reagent ruthenium red to detect pectic substances, the Sudan IV for lipids, and $10 \%$ ferric chloride for the detection of phenolic substances (Johansen, 1940).

Photosynthetic pigments: The contents for total chlorophyll $\left(\mathrm{Ch}_{\text {total }}\right)$, chlorophyll a $(\mathrm{Chl} a)$, chlorophyll $b(\mathrm{Chl} b)$, carotenoids (Carot) and the ratios $\mathrm{Chl} a: b$ and $\mathrm{Chl}_{\text {total }}$ Carot were calculated. From each plant, four leaf discs with diameter of $4.5 \mathrm{~mm}$ were homogenized in $5 \mathrm{~mL}$ of dimethyl-sulfonamide saturated with $\mathrm{CaCO}_{3}$ in test tubes spin-coated with aluminum foil and incubated at $60^{\circ} \mathrm{C}$ for $5 \mathrm{~h}$ (Wyka et al., 2007). Optical density readings were performed using a spectrophotometer (FEMT0, 700 Plus, SP) at 470, 663 and $645 \mathrm{~nm}$ and the concentrations of pigments determined by the equations of Lichtenthaler (1987).

Chlorophyll a fluorescence: Kinetics of fluorescence emission of $\mathrm{Chl}$ a was measured on a portable Handy PEA fluorometer (Plant Efficiency Analyzer, Hansatech, King's Lynn, Norkfolk, UK) using leaves that were pre-adapted to dark for 30 minutes. Measurements were taken between $800 \mathrm{~h}$ and $900 \mathrm{~h}$. Then, the leaves were exposed to a saturating pulse of red light at $3,000 \mathrm{mmol} \mathrm{m}^{-2} \mathrm{~s}^{-1}$. For each treatment, the fluorescence transient $0-\mathrm{J}-\mathrm{I}-\mathrm{P}$ was analyzed according to the J-I-P test (Strasser et al., 2004) using the Biolyzer software (Bioenergetics Laboratory, University of Geneva, Switzerland). The analyzed parameters were: (1) flow absorbance by active reaction center (RC) of PSII (ABS / RC), which may also represent the apparent size of an antenna of the active PSII; (2) specific flow of energy dissipated by the active PSII RC (DI/RC); and (3) efficiency or probability that a captured electron is transferred from the PSII Quinone $A\left(Q_{A}\right)$ to Quinone $B\left(Q_{B}\right)$ $\left[\mathrm{ET}_{0} / \mathrm{TR}_{0}\right.$ (time=0)]. We also evaluated the parameters related to energy conservation and efficiency of photochemical reactions: (1) the reduced number of $Q_{A}$ in RCs of the chlorophyll antenna of PSII (RC/ABS); (2) the maximum quantum yield of primary photochemical reactions PSII $\left[\phi P_{0}\left(=F_{V} / F_{M}\right)\right]$; and (3) the performance index for the conservation of energy of photons absorbed by PSII antenna to reduce $\mathrm{Q}_{\mathrm{B}}\left(\mathrm{PI}_{\mathrm{ABS}}\right)$ (Strasser et al., 2010).

Soluble carbohydrates: Secondary leaflets were frozen in liquid nitrogen, freeze dried and ground using a Micro-Wiley mill through 60 mesh sieves (ASTM, 2001). For approximately each $20 \mathrm{~g}$ of ground sample, $1 \mathrm{~mL}$ of ultrapure water was added and extraction took place in a water bath at $80^{\circ} \mathrm{C}$ for $1 \mathrm{~h}$. Samples were centrifuged for 10 min and the supernatant was concentrated in a Speed$\operatorname{Vac}^{\circledR}$ (Thermo Savant, USA). The residue was resuspended in ultrapure water to measure glucose (Glu), fructose (Fru), sucrose (Suc) and raffinose (Raf), using standards from Sigma ${ }^{\circledR}$. We used the phenolsulfuric method (Dubois et al., 1956) to determine the concentration of total soluble carbohydrates (TSC) using a spectrophotometer (Fento 490 plus) at $490 \mathrm{~nm}$. The rates of glucose from 0 to $50 \mathrm{mg}$ were used as standards. The levels of Glu, Fru, Suc and Raf were analyzed by HPAE-PAD (High Performance Anion Exchange-Pulsed Amperometric Detection), and the determinations were performed on a chromatograph (ICS 2500, HPLC Dionex ${ }^{\circledR}$ ). The carrier solvent used was $60 \mathrm{mM} \mathrm{NaOH}$ eluent and the cleaning agent was $200 \mathrm{mM} \mathrm{NaOH}$ with a flow rate of $1 \mathrm{~mL} \mathrm{~min}^{-1}$, and the system pressure of approximately $1,500 \mathrm{psi}$. The $25 \mathrm{~mL}$ samples were injected via the sample loop. The used column was the anion exchange Dionex ${ }^{\circledast}$ CarboPac PA1 (4x250 mm) with guard column CarboPac PA1 (4×50 $\mathrm{mm}$ ) and amperometric detector with gold electrode.

Plasticity index: The plasticity index (P.I.) represents the fraction of phenotypic variation of a given variable in relation to different environmental conditions (Valladares et al., 2002) ranging from 0 to 1 . The P.I. of each variable was calculated as the difference between the average minimum and maximum for each treatment (full sun and shade) divided by the maximum value (Valladares et al., 2000) before and after leaf abscission.

Statistical analysis: The results of fluorescence analysis were transformed into percentage based on control. For the other results, the analysis of variance 
(ANOVA One-Way) was performed and means were separated by Tukey's test $(p<0.05)$.

\section{RESULTS}

Leaf morphology: Profound structural and functional disturbances occurred in the first week of exposure to direct sunlight, where leaf abscission occurred. This is the alarm phase. On the following week, new leaf growth and recovery of functional losses indicated the resistance phase.

Starting on the second day of exposure to direct sunlight, secondary leaflets showed oxidation and burn (Figure 1), followed by total abscission of leaves.

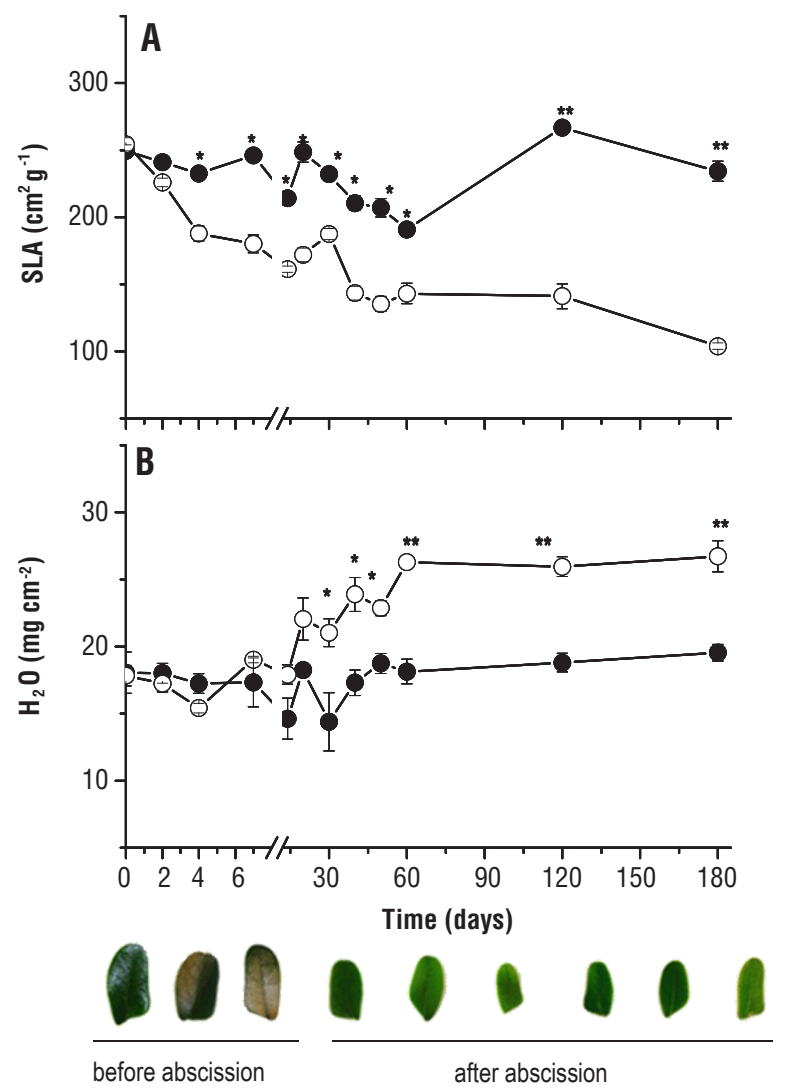

Figure 1. Specific leaf area $(A)$ and water content $(B)$ at 0,2 , $4,7,14,20,30,40,50,60,120$ and 180 days of transfer of C. echinata plants to shade $(\bullet)$ and full sun $(\bigcirc)$. Significant differences between light environments are indicated by asterisks (Tukey test at $p<0.05^{*}$ and $p<0.01^{* *}$, respectively). Vertical bars indicate standard error $(n=10)$. The secondary leaflets photos show burning before abscission, light color, and smaller area in the new secondary leaflets in relation to the initial time ( 0 days).
Between 7 and 14 days of exposure, new leaves with light green coloration and reduced area grew (Figure 1), with no death. Direct solar radiation caused a decrease in SLA within the first 48 hours. At 180 days, SLA reduction was $60 \%$ compared to the initial value and shade (Figure 1A). The $\mathrm{H}_{2} \mathrm{O}$ content of secondary leaflets did not differ between treatments before abscission. However, in comparison to control it was $38.8 \%$ higher in the new secondary leaflets grown under direct sunlight (Figure 1B). The $\mathrm{H}_{2} \mathrm{O}$ content reached the maximum value $\left(25 \mathrm{mg} \mathrm{cm}^{-2}\right)$ at 60 days and remained stable until the end of the experiment.

As for the anatomical features, the initial secondary leaflets showed reduced values of blade thickness (Figures 2A and 3D), cuticle (Figure 2B), adaxial epidermis (Figures $2 \mathrm{C}$ and $3 \mathrm{D}$ ), palisade parenchyma (Figures 2D and $3 \mathrm{D}$ ) and density of stomata (Figure 2F) after exposure to direct sunlight. Of these anatomical components, adaxial epidermis showed greater reduction, differing in $50 \%$ from the value of shaded plants. As for the spongy parenchyma, no significant differences were observed between treatments (Figure 2F).

The new secondary leaflets grown after abscission in plants exposed to direct sunlight showed different behavior (Figures 2 and 3 ). In general, all anatomical features examined increased after 10 days of exposure to direct sunlight, reaching the highest values at 60 days, especially those for palisade parenchyma thickness (143\% higher). Even with some variations, the values of tissue thickness, cuticle and density of stomata stayed stable at 180 days when the thickness of secondary leaflets and spongy parenchyma were $50 \%$ and $81.8 \%$ higher, respectively, in relation to shading. The density of stomata in plants exposed to direct sunlight was $57.9 \%$ higher than the shaded plants at 180 days. Both in the plants exposed to direct sunlight and in the shaded ones, the initial and new secondary leaflets grown after abscission had mesophyll with a single layer of palisade parenchyma (Figure 3A-D). Likewise, no significant differences were observed in the number of layers of spongy parenchyma cells, which ranged from four to six (Figure $3 \mathrm{C}$ and D). Phenolic compounds (Figure $3 \mathrm{C}$ ) were present in the epidermis of shaded plants (Figure $3 \mathrm{G}$ ) and in epidermis, and in cells of the palisade and spongy parenchyma of plants under direct sunlight (Figure $3 \mathrm{H}$ ).

Pigments and chlorophyll a fluorescence: The solar radiation caused the photo-oxidation of $\mathrm{Chl} \mathrm{a}$ on the second day, which was indicated by the decrease in the ratio $\mathrm{Chl} a: b$ (Figure 4A). This decrease was more pronounced at 60 days and continued to drop until the 


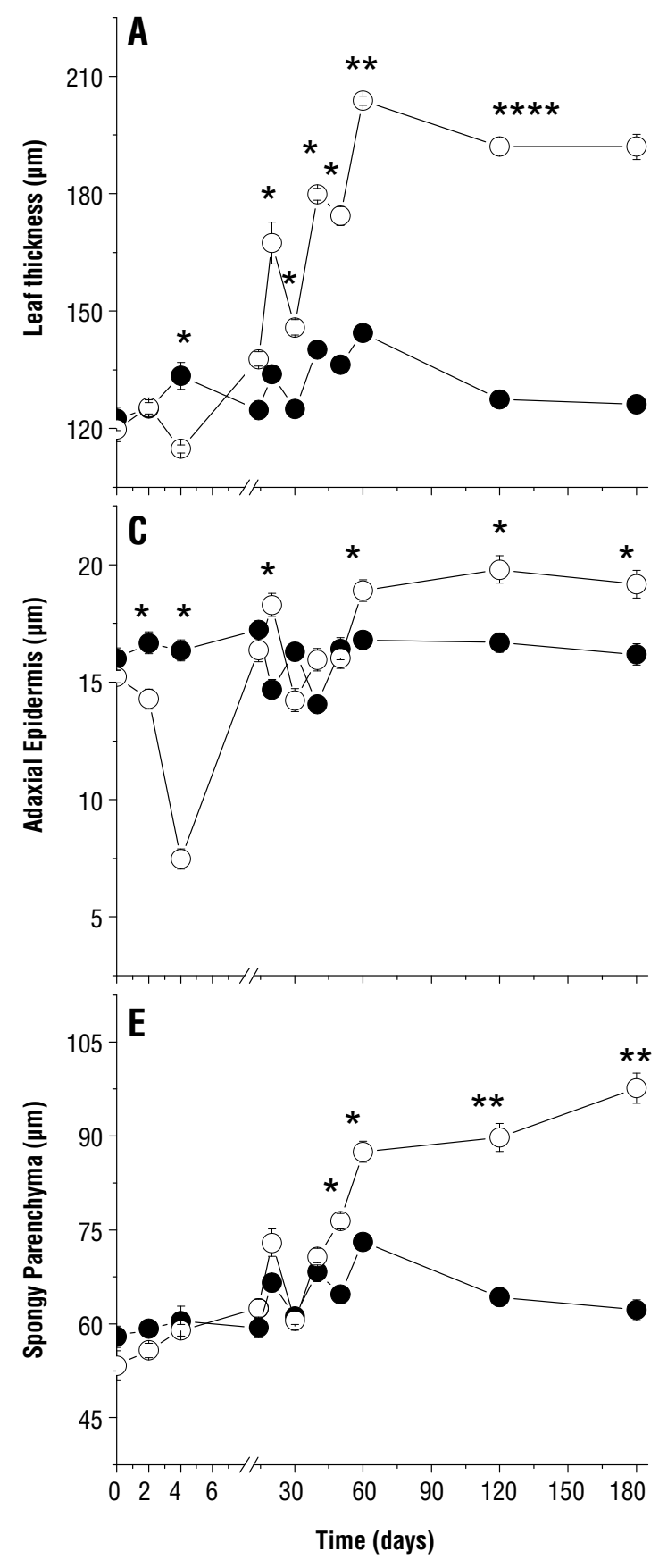

before abscission
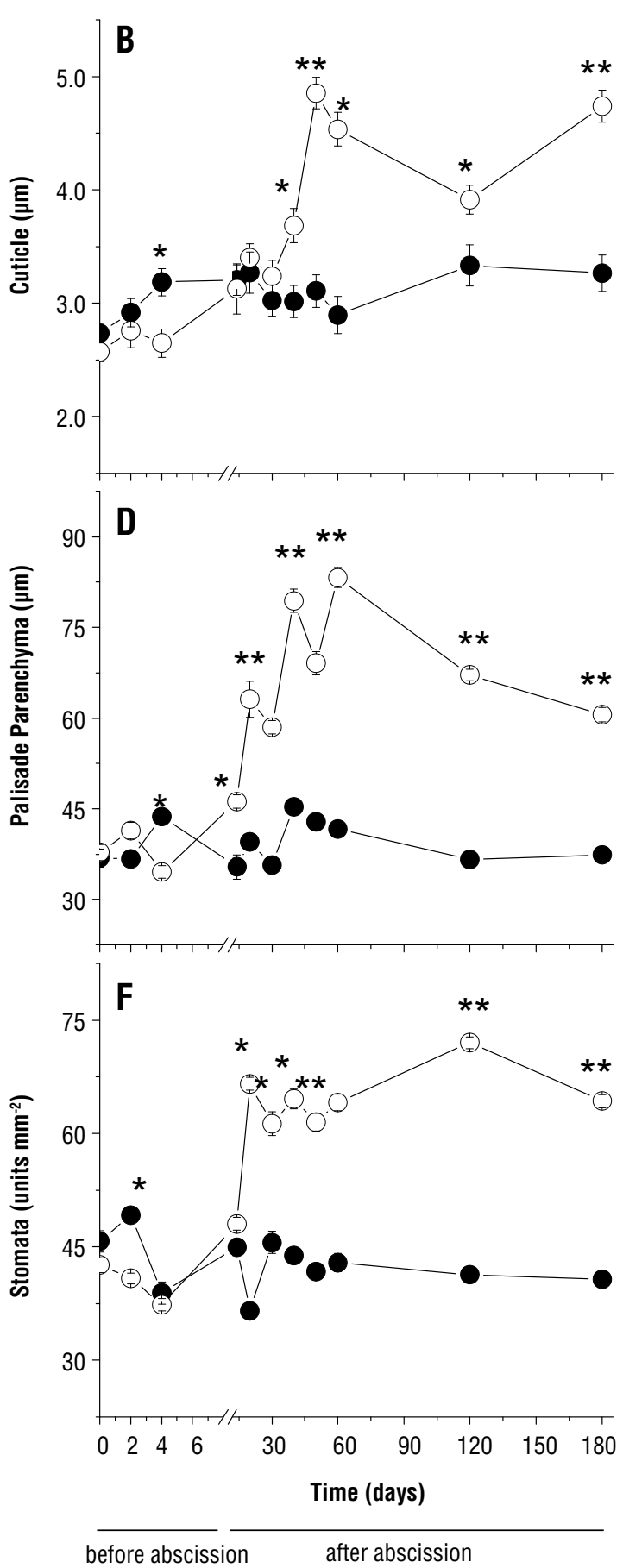

Figure 2. The secondary leaftles thickness $(A)$, cuticle $(B)$, adaxial epidermis $(C)$, palisade parenchyma (D), spongy parenchyma (E), and stomata density $(\mathrm{F})$ at $0,2,4,7,14,20,30,40,50,60,120$ and 180 days of transfer of $C$. echinata plants to shade (O) and full sun (O). Significant differences between light environments are indicated by asterisks (Tukey test at $p<0.05^{\star}$ and $p<0.01^{* *}$, respectively). Vertical bars indicate standard error $(n=20)$. 


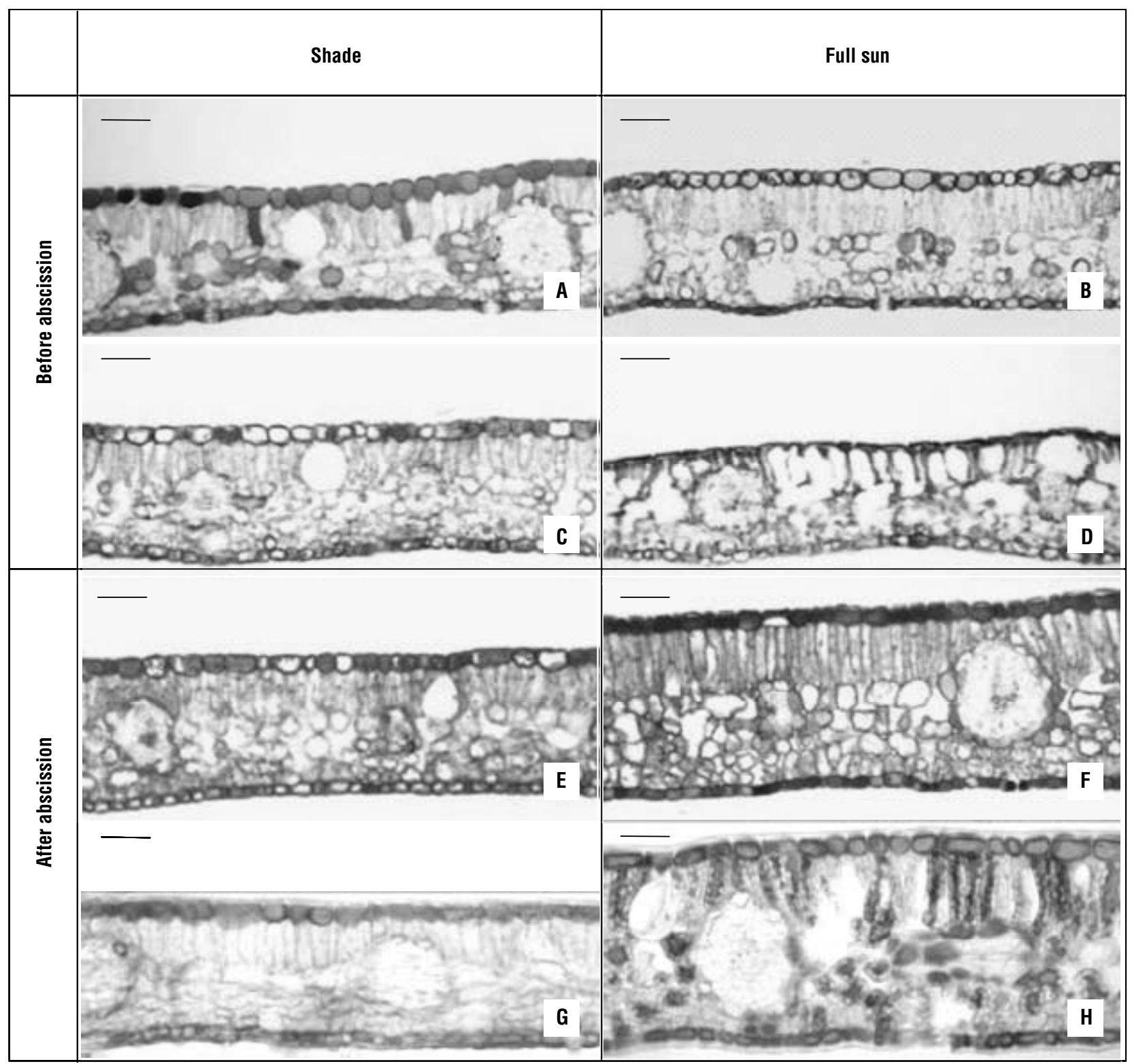

Figure 3. Cross-section of $C$. echinata leaflets grown under shade (left column) and exposed to full sun (right column). The thickness of leaflets in shade and full sun plants at $0(A, B), 4$ days $(C, D)$ and 60 days $(E, F)$ are showed. The histochemical test with ferric chloride showed the presence of phenolic compounds (brown) in the leaflet epidermis of plants in the shade (G) and epidermis, palisade and spongy parenchyma of plants in full sun $(\mathrm{H})$ at 180 days. Bar $=50 \mu \mathrm{m}$.

$180^{\text {th }}$ day, when the ratio was below 0.8 in the plants in full sun. A similar result was found in the ratio of $\mathrm{Chl}_{\text {total }}$ : Carot (Figure 4B). At 180 days, this ratio decreased from 2.7 in shaded plants to 1.8 in full sunlight plants.

Marked differences were found in the components of the $\mathrm{Chl}$ a fluorescence at the beginning of exposure to direct sunlight (Figure 5). We found an increase in ABS/ $\mathrm{RC}$ and $\mathrm{ET}_{0} / \mathrm{RR}_{0}$, simultaneously, with the increase in specific energy flow dissipated through the active $R C$ of PSII RC (DI/RC), reaching the highest values on the fourth day (Figure $5 \mathrm{~A}$ ). Prior to leaf abscission, there was a decrease in these variables. In new secondary leaflets these variables remained low and, by the end of the experiment, they had reached values equal to those of shaded plants (Figure 5A).

The reduction in maximum quantum yield of the primary photochemical reaction of $\mathrm{PSII}\left(\mathrm{F}_{\mathrm{V}} / \mathrm{F}_{\mathrm{M}}\right)$, in the 

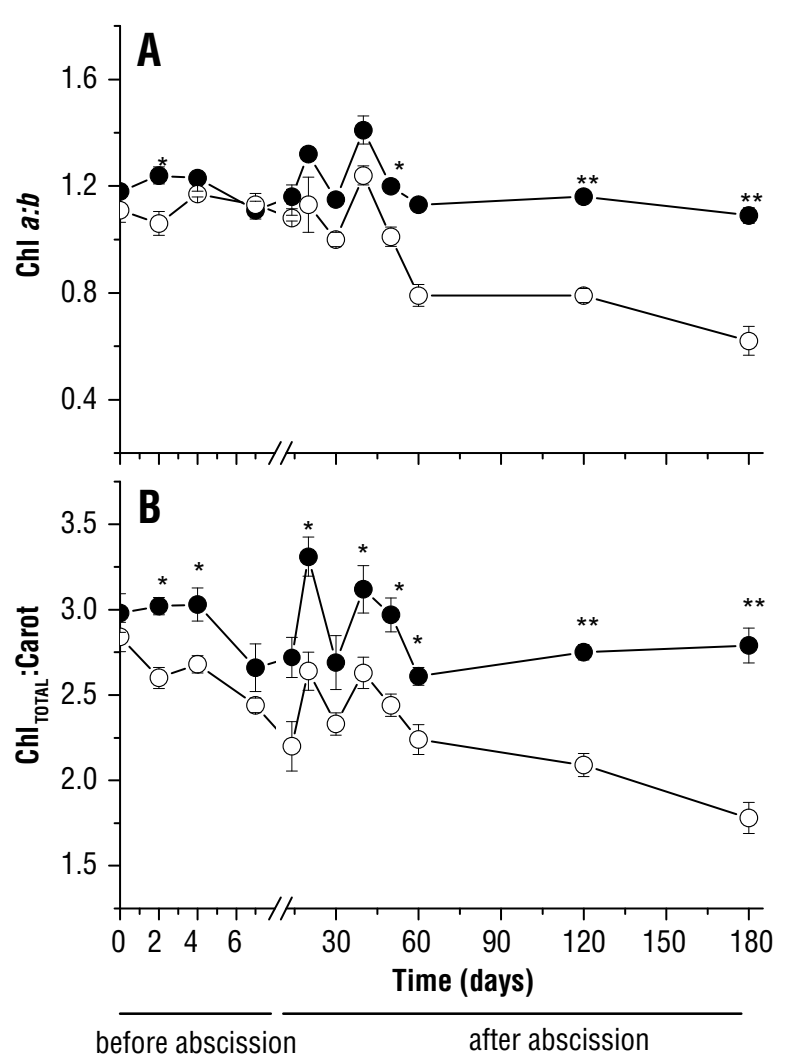

Figure 4. Chlorophyll a:Chlorophyll b ratio $(A)$ and Chlorophyll total:Carotonoids ratio (B) at 0, 2, 4, 7, 14, 20, 30, 40, 50, 60, 120 and 180 days of transfer the $C$. echinata plants to shade (o) and to full sun (○). Significant differences between light environments are indicated by asterisks (Tukey test at $p<0.05^{\star}$ and $p<0.01^{* *}$, respectively). Vertical bars indicate standard error $(n=7)$.

number of $Q_{A}$ reduced in $R C s$ by chlorophyll antenna of PSII (RC/ABS) and in the performance index $\left(\mathrm{PI}_{A B S}\right)$ was observed in early exposure to direct sunlight, reaching the lowest values on the fourth day (Figure 5B). In the moments prior to leaf abscission, these variables increased and remained high and close to control in the new secondary leaflets until the end of the experiment (Figure $5 B$ ). However, for $\mathrm{PI}_{\mathrm{ABS}}$, the reductions after the 20th day of full sun exposure were evident, reaching the lowest values at 60 days compared to control.

Soluble carbohydrates: The concentrations of Glu (Figure6A), Fru (Figure6B), Suc (Figure6C) and TSC (Figure6E) increased in the secondary leaflets that had been exposed to full sun before abscission. In secondary leaflets grown after abscission, the concentrations of Glu and Fru declined within the first days of exposure to direct sunlight, and were equal to those in the control group (Figure 6A and B). However, at 120 days the values were lower than those of control. At around 40

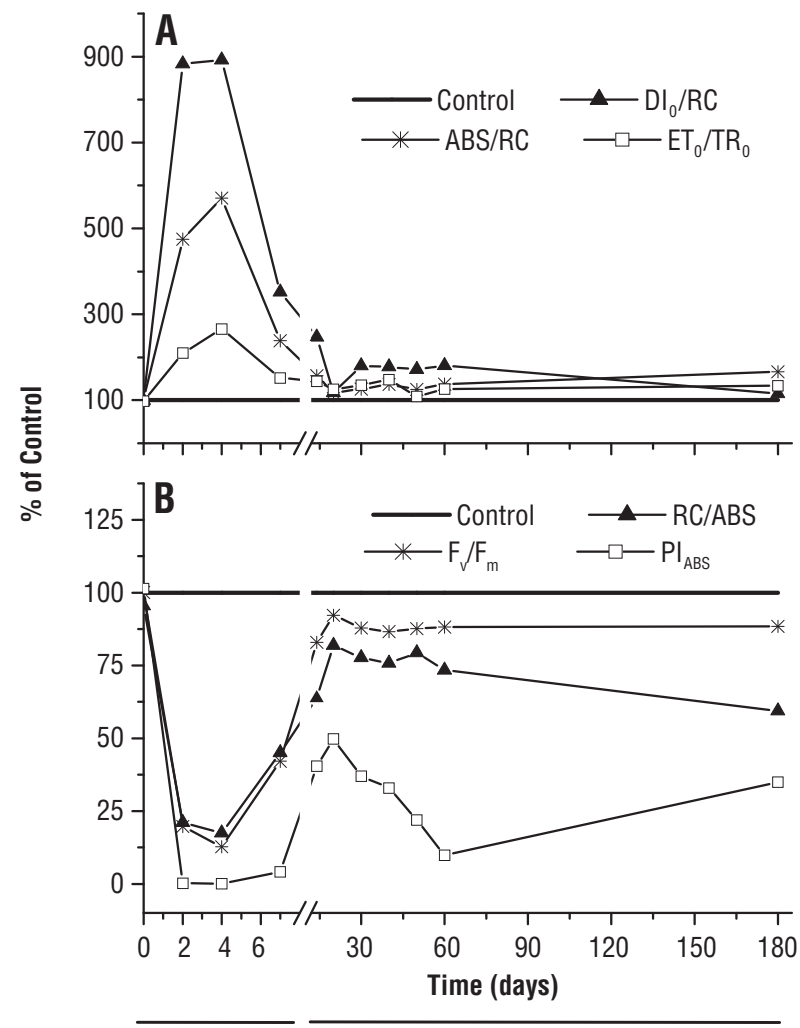

before abscission

after abscission

Figure 5. Chlorophyll a fluorescence emission at 0, 2, 4, 7, 14, $20,30,40,50,60,120$ and 180 days of transfer of $C$. echinata plants to shade (control) and to full sun. Values are expressed as percentage compared to control. (A) Energy dissipation by reaction center ( $\mathrm{DI} / \mathrm{RC})$, energy absorption by reaction center (ABS/RC), and the probability of a excitron captured by the PSII reaction center to move an electron in addition to $Q_{A}^{-}\left(E_{0} / T_{0}\right)$; (B) number the active reaction center of PSII and light absorbed by the antenna system ratio (RC/ABS), potential maximum quantum efficiency of PSII $\left(F_{v} / F_{m}\right)$ and index performance (P.I.) based on absorption $(n=7)$.

days, the concentration of Suc showed a second peak and then declined to control levels at 180 days. The pattern of TSC concentration (Figure 6E) was similar to that observed for Suc. Raf concentrations showed large fluctuations under the two lighting conditions (Figure 6D). However, the pattern was similar to that observed for Suc and TSC plants in full sunlight at 120 days. Unlike other carbohydrates, the concentration of Raf at 180 days was higher in plants in full sun. Peaks with the highest concentrations of each carbohydrate in plants exposed to full sun were different from those in shaded plants $(500 \%$ for Glu, $900 \%$ for Fru, $150 \%$ for Suc and TSC and $300 \%$ for Raf). Suc was the most representative carbohydrate, while Glu and Fru had intermediate values, and Raf showed the lowest ones. 

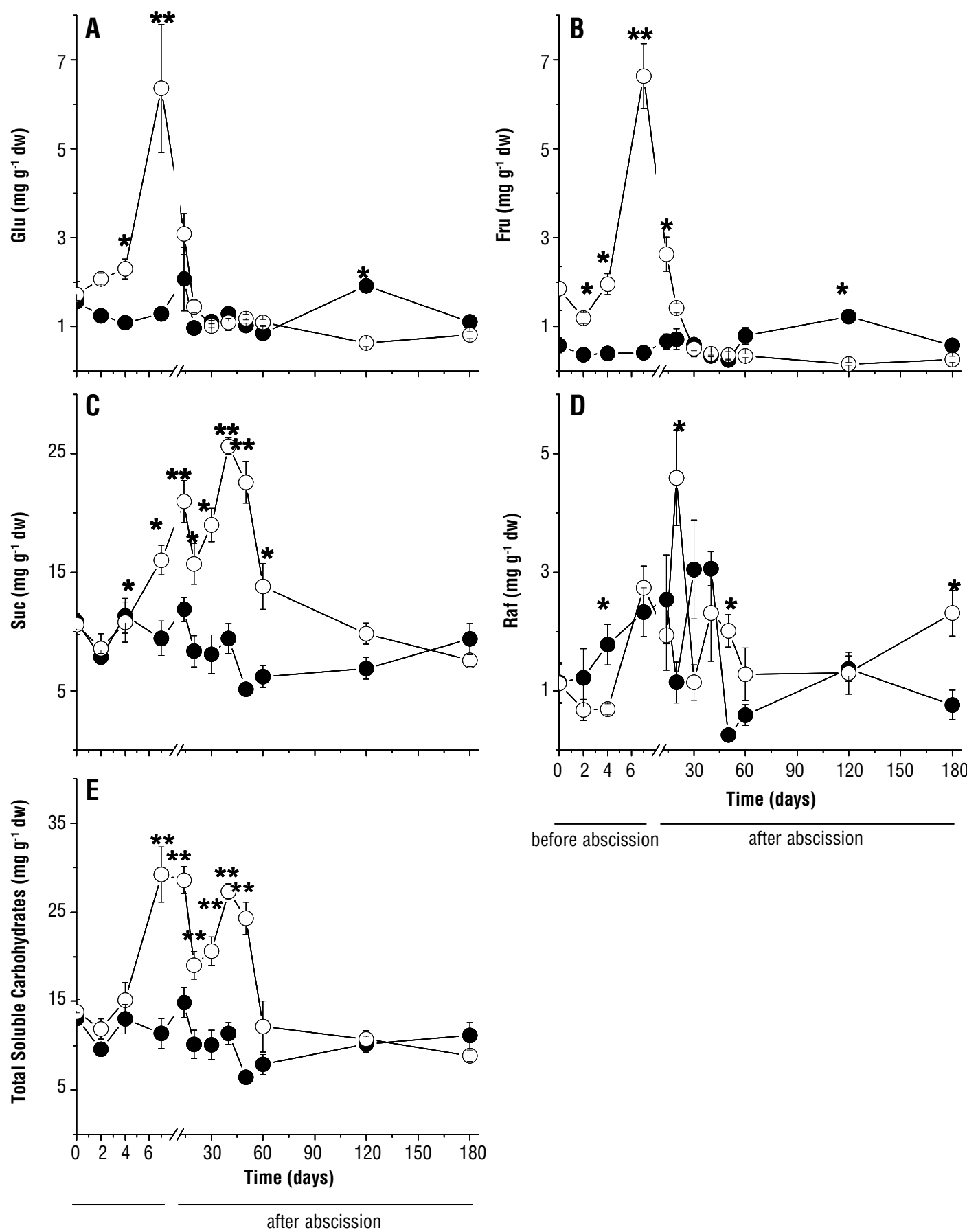

before abscission after abscission

Figure 6. Foliar concentration of soluble carbohydrates at $0,2,4,7,14,20,30,40,50,60,120$ and 180 days of transfer of $C$. echinata plants to shade (๑) and to full sun (O). (A) Glu, (B) Fru, (C) Suc, (D) Raf and (E) total soluble carbohydrates. Significant differences between light environments are indicated by asterisks (Tukey test at $p<0.05^{\star}$ and $p<0.01^{* *}$, respectively). Vertical bars indicate standard error ( $n=7$ ).

Analysis of phenotypic plasticity: The range of variation of P.I. was higher in leaves before abscission (Table 1), ranging from 0.02 to 0.96 . In the leaves after abscission, the change of P.I. was lower, from 0.12 to 0.67 . In the leaves before the abscission, photosynthesis (3) and biochemical/sugar (2b) variables contributed with the highest values of P.I. The morphological (1a), anatomical (1b) and biochemical/pigment (2a) variables showed lower plasticity in the leaves before abscission. However, within the variable type $1 \mathrm{~b}$, the adaxial epidermis thickness showed greater plasticity in relation to other variables of this group. The same applies to type $2 \mathrm{~b}$, whereas Raf showed lower plasticity than the other carbohydrates. 
Table 1. Plasticity index to light response [P.I.= (maximum -minimum)/maximum] according to Valadares et al. (2002). Morphological (1a), anatomical (1b), biochemical/pigment (2a), biochemical/sugar (2b), and photosynthetic (3) variables in plants of $C$. echinata. Variables exhibiting significant differences between light environments are indicated by an asterisk (Tukey test, $p<0.05)$.

\begin{tabular}{lccc}
\hline \multirow{2}{*}{ Variable } & \multirow{2}{*}{$\begin{array}{c}\text { Variable } \\
\text { Type }\end{array}$} & $\begin{array}{c}\text { Plasticity index } \\
\text { abscission }\end{array}$ & $\begin{array}{c}\text { After } \\
\text { abscission }\end{array}$ \\
\hline Specific leaf area (SLA) & $1 \mathrm{a}$ & $0.19^{*}$ & 0.56 \\
Relative water content (turgor) & $1 \mathrm{a}$ & $0.09^{*}$ & 0.27 \\
Leaf thickness & $1 \mathrm{~b}$ & $0.14^{*}$ & 0.34 \\
Cuticle thickness & $1 \mathrm{~b}$ & $0.17^{*}$ & 0.31 \\
Adaxial epidermis thickness & $1 \mathrm{~b}$ & $0.54^{*}$ & 0.16 \\
Palisade parenchyma thickness & $1 \mathrm{~b}$ & $0.21^{*}$ & 0.38 \\
Spongy parenchyma thickness & $1 \mathrm{~b}$ & $0.02^{*}$ & 0.36 \\
Stomatal density & $1 \mathrm{~b}$ & $0.04^{*}$ & 0.37 \\
Chlorophyll a:b ratio & $2 \mathrm{a}$ & $0.02^{*}$ & 0.43 \\
Chlorophyll:Carotenoids ratio & $2 \mathrm{a}$ & $0.08^{*}$ & 0.36 \\
Glucose & $2 \mathrm{~b}$ & $0.80^{*}$ & 0.27 \\
Fructose & $2 \mathrm{~b}$ & $0.94^{*}$ & 0.54 \\
Sucrose & $2 \mathrm{~b}$ & $0.41^{*}$ & 0.19 \\
Raffinose & $2 \mathrm{~b}$ & $0.15^{*}$ & 0.67 \\
Total soluble carbohydrates & $2 \mathrm{~b}$ & $0.61^{*}$ & 0.20 \\
ABS/RC $_{\text {B }}$ & 3 & 0.58 & 0.40 \\
DI/RC & 3 & $0.72^{*}$ & 0.14 \\
TR $_{0} / \mathrm{ET}$ & 3 & 0.34 & 0.25 \\
RC/ABS & 3 & 0.55 & 0.41 \\
$\mathrm{~F}_{\mathrm{V}} / \mathrm{F}_{\mathrm{M}}$ & 3 & $0.58^{*}$ & 0.12 \\
$\mathrm{Pl}_{\text {ABS }}$ & 3 & 0.96 & 0.65 \\
\hline & & &
\end{tabular}

The P.I. of morphological (type 1a), anatomical (1b) and biochemical/pigment (2a) variables in the leaves after abscission increased compared to the leaves before abscission. However, the variable for anatomical adaxial epidermis thickness was lower in comparison to the leaves before abscission. The photosynthesis and biochemical/ sugar variables decreased in the leaves after abscission when compared with leaves before abscission, except for Raf, which presented higher P.I. in these new leaves.

\section{DISCUSSION}

Leaf abscission is a commonly observed damage in shade species exposed to high solar irradiance. In C. echinata, the total leaf abscission occurred within the first seven days, which confirmed the observation by Mengarda et al. (2009). However, this effect is not always observed in shade plants. In this sense, the species Ouratea lucens (Ochnaceae) of the understory in a tropical rainforest of Panama showed moderate photoinhibition, keeping most of its leaves intact (Kursar and Coley, 1999). Therefore, leaf abscission caused by high irradiance is not the best indicator to classify the species as shade plants or sun plants. Thus, other morphological and physiological variables need to be evaluated.

Acclimation to high irradiance may occur early in the leaves (Oguchi et al., 2005), as observed in C. echinata in full sun, in which the P.I. of biochemical/carbohydrates and variables on photosynthesis were higher. On the other hand, the P.I. of morphological (SLA, anatomical components and water content) and biochemical (photosynthetic pigments) components were higher in new leaves, confirming earlier reports according to which the highest adaptations occur in the leaves in full sun (Kursar and Coley, 1999; Wyka et al., 2007).

The reduction of SLA is a remarkable response in species with more advanced categories of forest succession that are subject to high irradiance (Souza and Válio, 2003), as observed in $C$. echinata. In this species, the decrease in SLA and the increase of stomatal density implies less water loss, demonstrated by higher $\mathrm{H}_{2} \mathrm{O}$ contents in the new leaflets. These characteristics associated with greater leaf thickening may have minimized the photo-oxidative damage (Poorter and Nagel, 2000; Valladares et al., 2005) of $C$. echinata in the resistance phase. In this respect, the palisade and spongy parenchyma contributed to greater leaf thickening showing the plasticity of these tissues under conditions of brightness contrast.

In addition to the anatomical changes, variations in secondary metabolite content in plants may occur under intense irradiance. Phenolic compounds and flavonoids tend to accumulate in the epidermis and mesophyll of tropical trees under intense irradiance (Melgar et al., 2009), as observed in plants of $C$. echinata in full sun. However, the presence of phenols was also observed in the epidermis of leaves of $C$. echinata under shade. The accumulation of phenols, especially quercetin glycosides luteolin, indicates an efficient antioxidative defense system (Guidi et al., 2008) acting in the scavengers of several reactive oxygen species (ROS) and singlet $\mathrm{O}_{2}$ in the chloroplasts of plants under intense irradiance (Melgar et al., 2009).

Changes in photosynthetic pigments were also observed in secondary leaflets of $C$. echinata. The decrease in the ratios $\mathrm{Chl} a: b$ and $\mathrm{Ch}_{\text {total }}$ :Carot in plants of C.echinata after periods of exposure to direct sunlight (Figure 4) is one of the immediate responses of shade species when exposed to higher irradiance (Demmig-Adams and Adams, 2006; Morais et al., 2007; Magalhães et al., 2009), which indicates decreased supply of energy for the 
light-gathering antennas (Kitajima and Hogan, 2003; Laisk et al., 2005; Magalhães et al., 2009). This strategy protects the photosystems from photo-oxidative damage caused by high irradiance (Tan et al., 2000; Marenco et al., 2001; Reyes-Díaz et al., 2009). However, the continuous reduction in photosynthetic pigments after exposure of $C$. echinata to full sunlight shows its preference for less illuminated environments.

The degradation of photosynthetic pigments was reflected on Chlaflurescence parameters. The fast reduction in $F_{V} / F_{M}$ of $C$. echinata under high irradiance was also observed in other tropical trees under intense irradiance (Gonçalves et al., 2007; Magalhães et al., 2009). Similarly, the recovery time of $F_{v} / F_{M}$ was also fast, especially when compared to other tropical species, such as Minquartia guianensis (Magalhães et al., 2009) and Aniba rosaeodora (Gonçalves et al., 2007), whose recovery time was 30 and 60 days, respectively. For $C$. echinata, the recovery of the maximum quantum yield of primary photochemical reactions of $P S I I$, the number of $Q_{A}$ reduced by $R C s$ in the antenna chlorophyll of PSII (RC/ABS) and performance index $\left(\mathrm{PI}_{\mathrm{ABS}}\right)$ started in the last three days prior to abscission and was completed on the $20^{\text {th }}$ day in the new leaflets. Such responses are typical of plants fitted with mechanisms able to prevent and repair photosynthesis damage under stress conditions (Wilhelma and Selmar, 2011). However, even with the recovery of fluorescence parameters in the final alarm phase, the secondary leaflets of $C$. echinata showed burns followed by abscission. These results suggest that the recovery of photosynthesis could not prevent the synthesis and/or the action of substances that cause cell death. This hypothesis is sustained by the fact that under intense irradiation, photosynthetic electrons can form highly reactive oxygen radicals able to degrade proteins, pigments, lipids and nucleotides, causing irreversible damage (Srivastava et al., 1999).

In addition to being considered an excellent tool to study the physiology of stress, the analyses of $\mathrm{Chl}$ a fluorescence can be a tool for selecting species that are tolerant to high irradiance (Gonçalves and Santos Jr., 2005). In this respect, strong destabilization of the parameters of $\mathrm{Chl}$ a fluorescence of $C$. echinata in the alarm phase confirms that this species is less adapted to populating more illuminated environments (Geßler et al., 2005). Thus, the decrease in photosynthetic pigments with the prolongation of exposure to direct sunlight, the $\mathrm{F}_{\mathrm{V}} / \mathrm{F}_{\mathrm{M}}$ and $\mathrm{PI}_{\mathrm{ABS}}$ photodamage and total leaf abscission in the alarm phase are strong indicators that C. echinata is a more advanced species in forest succession, as suggested by Mengarda et al. (2009).

Changes in $\mathrm{Chl}$ a fluorescence seem to have been reflected on the concentrations of soluble carbohydrates of $C$. echinata in full sun. The greater participation of the Glu and Fru in the alarm phase, and of Suc and Raf in the resistance phase, suggest the action of these primary metabolites as molecular flags (Valladares et al., 2005; Conde et al., 2007) and physiological and morphological models (Gibson, 2004) in plants under stress. On the other hand, Glu, Fru and Suc could act in osmoregulation of leaf tissues of $C$. echinata as demonstrated in other trees under intense irradiance (Aranda et al., 2001; Valladares et al., 2005), Raf is involved in the antioxidant action in stressful conditions (Nishizawa et al., 2008). The peaks of Suc in the new leaflets in full sun may have contributed to water entry, thus increasing the volume of palisade and spongy parenchyma cells in the resistance phase. This hypothesis is based on the statement that the high Suc concentration reduces osmotic potential and promotes the elongation of mesophyll cells (Terashima etal., 2006). Thus, higher $\mathrm{H}_{2} \mathrm{O}$ content and cell elongation regulated by Suc appears to have caused, ultimately, SLA decrease after exposure to full sun.

Although the concentration of TSC plants in full sun has declined between 60 and 180 days without a significant difference compared to control, the water content of secondary leaflets remained greater in plants in full sun. This may have been caused by factors such as increased thickening of the cuticle, stomatal density and elongation of mesophyll cells of $C$. echinata under direct sunlight, thus offering greater resistance to water loss (Dickison, 2000; Oguchi et al., 2003; 2005).

The decrease in the concentration of Glu and Fru in the early resistance phase coincided with the growth of new leaves, which suggests the use of these monosaccharides to meet the energy demand in the renewed growth phase. With the decrease of these carbohydrates to very low levels, Suc has become the main energy molecule to be metabolized in cell respiration, which suggests that catabolism increased in comparison to anabolism after prolonged exposures of $C$. echinata to full sun. This suggests a metabolic strategy in the attempt to repair the photodamage in the resistance phase.

In addition to the energy metabolism, the monosaccharides, disaccharides and RFOs were also related to the antioxidant, acting as scavengers (Mendes et al., 2001; Melgar et al., 2009) and inhibitors of the synthesis of ROS (Coueé et al., 2006) under different kinds of stress. Therefore, the investigation of antioxidative metabolism and its relations with the soluble carbohydrates could provide important information to understande the mechanisms of adaptation of shade-tolerant tropical trees when exposed to intense irradiance. 
We can conclude that the strong photo-oxidative damage did not affect the survival of $C$. echinata plants under full sun. In part, this effect can be attributed to the lower SLA, the higher turgescence and plasticity of the components of anatomic of leaflets grown in the resistance phase. In this phase, the possible relationship with the osmoregulation of Suc and Raf with the antioxidant action appears to have a key role in the regulation of morphological and physiological adaptations of new leaflets and inhibition of leaf abscission. Still, C. echinata cannot be considered as a high irradiance-tolerant species, because of its total leaf abscission in the alarm phase and continuous reduction of photosynthetic pigments in the resistance phase. Moreover, we cannot discard the water factor. The plants were watered regularly, which does not occur naturally in a tropical forest. In any case, the results obtained in the experimental conditions of this study indicate that $C$. echinata is a shade plant or a species in a more advanced category of forest succession. Another factor that supports this conclusion is that the seeds of C. echinata may lose viability in less than three months under normal environmental conditions, demonstrating that it requires humid environments to germinate, which are conditions found within a forest. All these data allow us to classify $C$. echinata as a late or climax species in forest succession.

\section{ACKNOWLEDGMENTS}

Thanks are owed to Biodiversitas FoundationBrazil, Foundation for Scientific and Technological Support of the City of Vitoria-Brazil (FACITEC-Procedure 38/2007) and the Research Support Foundation of Espírito Santo, Brazil (FAPES Process-39044823/2007) for financial support; and to Professor Dr. Carlos Alberto Labate , of the Genetic Plants Max Feffer Laboratory/ESALQ/USP for the carbohydrate analyses. The first author would like to thank FACITEC for the postgraduate scholarship provided.

\section{REFERENCES}

Aranda I, Gil L, Pardos J (2001) Effects of thinning in a Pinus sylvestris L. stand on foliar water relations of Fagus sylvatia L. seedlings planted within the pinewood. Trees 15:358-364.

ASTME 1758-01 (2001) Standard practice for preparation of biomass for compositional analysis. In: 2004 Annual Book of Standards, v. 11.05. American Society for Testing and Materials, West Conshohocken, PA.

Coueé I, Sulmon C, Gouesbet G, Amrani AE (2006). Involvement of soluble sugars in reactive oxygen species balance and responses to oxidative stress in plants. J. Exp. Bot. 57:449-459.
Conde C, Silva P, Agasse A, Lemoine R, Delrot S, Tavares R, Gerós (2007) Utilization and transport $f$ mannitol in Olea europaea and implications for salt stress tolerance. Plant Cell Physiol. 48:42-53.

Demmig-Adams B, Adams WW (2006) Photoprotection in an ecological context: the remarkable complexity of thermal energy dissipation. New Phytol. 172:11-21.

Dickison WC (2000) Integrative Plant Anatomy. Academic Press, London.

Dubois M, Gilles KA, Hamilton JK, Rebers PA, Smith F (1956) Colorimetric method for the determination of sugars and related substances. Anal. Chem. 28:350-356.

Gerrits P0. The application of glycol methacrylate in histotechnology; some fundamental principles. Germany: Department of Anatomy and Embriology, State University of Gröningen; 1991.

Geßler A, Duarte HM, Franco AC, Lüttge U, Mattos EA, Nahm M, Rodrigues PJEP, Scarano FR, Rennenberg H (2005) Ecophysiology of selected tree species in different plant communities at the periphery of the Atlantic Forest of SE - Brazil III. Three legume trees in a semi-deciduous dry forest. Trees. 19:523-530.

Gibson SI (2004) Sugar and phytohormone response pathways: navigating a signalling network. J. Exp. Bot. 55:253-264.

Gonçalves JFC, Santos Jr. UM (2005) Utilization of the chlorophyll a fluorescence technique as a tool for selecting tolerant species to environments of high irradiance. Braz. J. Plant Physiol. 17:307-313.

Gonçalves JFC, Barreto DCS, Santos Jr. UM, Fernandes AV, Sampaio PTB, Buckeridge MS (2005) Growth, photosynthesis and stress indicators in young rosewood plants (Aniba rosaeodora Ducke) under different light intensities. Braz. J. Plant Physiol. 17:325-334.

Gonçalves JFC, Santos Jr. UM, Nina Jr. AR, Chevreuil LR (2007) Energetic flux and performance index in copaiba (Copaifera multijuga Hayne) and mahogany (Swietenia macrophylla King) seedlings grown under two irradiance environments. Braz. J. Plant Physiol. 19:171-184.

Guidi L, Degl'Innocenti E, Remorini D, Massai R, Tattini M (2008) Interactions of water stress and solar irradiance on the physiology and biochemistry of Ligustrum vulgare. Tree Physiol. 28:873-883.

Hunt R (1982) Plant growth curves: the functional approach to plant growth analysis. Edward Arnold Publishers, London.

Johansen DA (1940) Plant Microtechnique. McGraw-Hill Co., New York.

Kitajima K, Hogan KP (2003) Increases of chlorophyll a/b ratios during acclimation of tropical woody seedlings to nitrogen limitation and high light. Plant Cell Environ. 26:857-865.

Kitao M, Lei TT, Koike T, Tobita H, Maruyama Y (2000) Susceptibility to photoinhibition of three deciduous broadleaf tree species with different successional traits raised under various light regimes. Plant Cell Environ. 23:81-89.

Kursar TA, Coley PD (1999) Contrasting modes of light acclimation in two species of the rainforest understory. Oecologia 121:489-498.

Laisk A, Eichelmann H, Oja V, Rasulov B, Padu E, Bichele I, Pettai H, Kull 0 (2005) Adjustment of leaf photosynthesis to shade in a natural canopy: rate parameters. Plant Cell Environ. 28:375-388.

Lambers H, Poorter H (2004) Inherent variation in growth rate between higher plants: a search for physiological causes and ecology consequences. Adv Ecol Res. 34:283-362.

Lichtenthaler HK (1987) Chlorophylls and carotenoids: pigments of photosynthetic biomembranes. Methods Enzimol. 148:350-381.

Longui EL, Lombardi DR, Alves ES (2010) Potential Brazilian wood species for bows of string instruments. Holzforschung 64:511-520. 
Magalhães NS, Marenco RA, Mendes KR (2009) Aclimatação de mudas de acariquara à alta irradiância. Pesq. Agropec. Bras. 44:687-694.

Marenco RA, Gonçalves JF, Vieira G (2001) Leaf gas exchange and carbohydrates in tropical trees differing in successional status in two light environments in central Amazonia. Tree Physiol. 21:1311-1318.

Matsuki S, Ogawa K, Tanaka A, Hara T (2003) Morphological and photosynthetic responses of Quercus crispula seedlings to high-light conditions. Tree Physiol. 23:769-775.

Melgar JC, Guidi L, Remorini D, Agati G, Degl'Innocenti E, Castelli S, Baratto MS, Faraloni C, Tattini M (2009) Antioxidant defences and oxidative damage in salt-treated olive plants under contrasting sunlight irradiance. Tree Physiol. 29:1187-1198.

Mendes MM, Gazarini LC, Rodrigues ML (2001) Acclimation of Myrtus communis to contrasting Mediterranean light environments - effects on structure and chemical composition of foliage and plant water relations. Environ. Exp. Bot. 45:165-178.

Mengarda LHG, Souza RLF, Campostrini E, Reis FO, Vendrame WA, Cuzzuol GRF (2009) Light as an indicator of ecological succession in brazilwood (Caesalpinia echinata Lam.). Braz. J. Plant Physiol. 21:55-63.

Morais RR, Gonçalves JFC, Santos Jr. UM, Dünisch 0, Santos ALW (2007) Chloroplastid pigment contents and chlorophyll a fluorescence in Amazon tropical three species. Rev. Árvore. 31:959-966.

Niinemets U, Kull 0, Tenhunen JD (1998) An analysis of light effects on foliar morphology, physiology and light interception in temperate deciduous woody species of contrasting shade tolerance. Tree Physiol. 18:681-696.

Nishizawa A, Yabuta Y, Shigeoka S (2008) Galactinol and raffinose constitute a novel function to protect plants from oxidative damage. Plant Physiol. 147:1251-1263.

O'Brien TP, Feder N, McCully ME (1964) Polychromatic staining of plant cell walls by toluidine blue 0. Protoplasma 59:368-373.

Oguchi R, Hirosaka K, Hisose T (2003) Does the photosynthetic light-acclimation need change in leaf anatomy? Plant Cell Environ. 26:505-512.

Oguchi R, Hirosaka K, Hisose T (2005) Leaf anatomy as a constraint for photosynthetic acclimation: differential responses in leaf anatomy to increasing growth irradiance among three deciduos trees. Plant Cell Environ. 28:916-927.

Parida AK, Das AB, Mittra B (2004) Effects of salt on growth, ion accumulation, photosynthesis and leaf anatomy of the mangrove, Bruguiera parviflora. Trees 18:167-174.

Peterbauer T, Richter A (2001) Biochemistry and physiology of raffinose family oligosaccharides and galactosyl cyclitols in seeds. Seed Sci. Res. 11:185-197.

Poorter H, Nagel $\mathrm{O}$ (2000) The role of biomass allocation in the growth response of plants to different levels of light, $\mathrm{CO}_{2}$, nutrients and water: a quantitative review. Aust. J. Plant Physiol. 27:595-607.

Reyes-Díaz M, Ivanov AG, Huner NPA, Alberdi M, Corcuera LJ, Bravo LA (2009) Thermal energy dissipation and its components in two developmental stages of shade-tolerants species, Nothofagus nitida, and a shadeintolerant species, Nothofagus dombeyi. Tree Physiol. 29:651-662.
Souza RP, Válio IFM (2003) Seedling growth of fifteen Brazilian tropical tree species differing in sucessional status. Rev. Bras. Bot. 26:35-47.

Srivastava A, Strasser RJ, Govindjee (1999) Greening of peas: parallel measurements of $77 \mathrm{~K}$ emission spectra, OJIP chlorophyll a fluorescence, period four oscillation of the initial fluorescence level, delayed light emission, and P700. Photosynthetica 37:365-392.

Stocker 0 (1947) Probleme der Pflanzlichen Dürreresistenz. Naturwissenschaften 34:326-371.

Strasser RJ, Tsimilli-Michael M, Srivastava A (2004) Analysis of the fluorescence transient. In: George C, Papageorgiou C, Govindjee (eds), Chlorophyll Fluorescence: a signature of photosynthesis, pp. 321-362. Advances in Photosynthesis and Respiration Series. Springer, Dordrecht.

Strasser RJ, Tsimilli-Michael M, Qiang S, Goltsev V (2010) Simultaneous in vivo recording of prompt and delayed fluorescence and 820 -nm reflection changes during drying and after rehydration of the resurrection plant Haberlea rhodopensis. Biochim Biophys Acta. 1797:1313-1326.

Tan Y, Jian-Hui J, Hai-Long WU, Cui H, Yu-Ru Q (2000) Resolution of kinetic system of simultaneous degradation of chlorofill $a$ and $b$ by Parafac. Anal. Chem. Acta. 412:195-202.

Tattini M, Remorini D, Pinelli P, Agati G, Saracini E, Traversi ML, Massai R (2006) Morpho-anatomical, physiological and biochemical adjustments in response to root zone salinity stress and high solar radiation in two Mediterranean evergreen shrubs, Myrtus communis and Pistacia Ientiscus. New Phytol. 170:779-794.

Terashima I, Hanba YT, Tazoe Y, Vyas P, Yano S (2006) Irradiance and phenotype: comparative eco-development of sun and shade leaves in relation to photosynthetic $\mathrm{CO}_{2}$ diffusion. J. Exp. Bot. 57:343-354.

Urban 0, Kosvancová M, Marek MV, Lichtenthaler HK (2007) Induction of photosynthesis and importance of limitations during the induction phase in sun and shade leaves of five ecologically contrasting tree species from the temperate zone. Tree Physiol. 27:1207-1215.

Valladares F, Wright SJ, Lasso E, Kitajima K, Pearcy RW (2000) Plastic phenotypic response to light of 16 congeneric shrubs from a Panamanian rainforest. Ecology 81:1925-1936.

Valladares F, Balaquear L, Martínez-Ferri E, Perez-Corona E, Manrique E (2002) Plasticity, instability and canalization: is the phenotypic variation in seedlings of sclerophyll oaks consistent with the environmental unpredictability of Mediterranean ecosystems? New Phytol. 156:457-467.

Valladares F, Arrieta S, Aranda I, Lorenzo D, Sánchez-Gómez D, Tena D, Suárez F, Pardos JA (2005) Shade tolerance, photoinhibition sensitivity and phenotypic plasticity of Ilex aquifolium in continental Mediterranean sites. Tree Physiol. 25:1041-1052.

Wilhelma C, Selmar D (2011) Energy dissipation is an essential mechanism to sustain the viability of plants: the physiological limits of improved photosynthesis. J. Plant Physiol. 168:79-87.

Wyka T, Robakowski P, Zytkowiak R (2007) Acclimation of leaves to contrasting irradiance in juvenile trees differing in shade tolerance. Tree Physiol. 27:1293-1306. 